Alberto Hijazo-Gascón e Iraide Ibarretxe-Antuñano

Departamento de Lingüística General e Hispánica

Facultad de Filosofía y Letras

C/ Pedro Cerbuna, 12

50009 Zaragoza

Universidad de Zaragoza

\title{
LAS LENGUAS ROMÁNICAS Y LA TIPOLOGÍA DE LOS EVENTOS DE MOVIMIENTO*
}

\begin{abstract}
:
According to Talmy's semantic typology, Romance languages are classified as verbframe. This group of languages lexicalizes Path information in the main verb, whereas Manner information, if expressed at all, is usually codified in linguistic elements outside the main verb. Based on a detailed study on oral data from motion events in three Romance languages (Spanish, Italian, and French in contrast with a Germanic language: German), this paper explores the existence of intratypological variation in the description of motion events in these languages. Results show that the three languages behave similarly with respect to the Manner component, but that there is intratypological variation as far as the Path component is concerned. Italian can be considered as high-path salient language, since it is significantly different from Spanish and French.
\end{abstract}

Key words: intratypological variation, Manner, motion events, Path, Romance languages.

1. Movimiento y espacio en la tipología semántica

\footnotetext{
* Esta investigación ha sido financiada por el Ministerio de Innovación y Ciencia, Gobierno de España (Proyecto MovEs, FFI2010-14903).
} 
En la tipología semántica, el análisis de los eventos de movimiento es una de las áreas de investigación más fructíferas posiblemente, entre otras razones, porque todas las lenguas tienen diferentes recursos y mecanismos lingüísticos para la expresión del movimiento. Es por ello que el análisis contrastivo es tremendamente interesante, tanto para buscar similitudes como diferencias. La propuesta de Talmy $(1991,2000)$ para estudiar y clasificar desde un punto de vista tipológico los eventos de movimiento es una de las más influyentes actualmente.

Según este autor, un evento de movimiento se define como una situación que contiene movimiento o en la que se permanece en una situación estacionaria. Se pueden caracterizar a través de una serie de componentes semánticos. Estos serían cuatro: la Figura, la entidad que realiza el movimiento, la Base o fondo sobre el cual se mueve la Figura, el Movimiento que es la presencia o la ausencia de movimiento en sí misma, y el Camino, que se definiría como la trayectoria que sigue la Figura. Además, como en cualquier otro evento, existen dos componentes semánticos secundarios, que también pueden participar en la caracterización conceptual del movimiento: la Manera, es decir, la forma en la que se desarrolla el evento, y la Causa, que provoca el movimiento.

Talmy arguye que las lenguas se pueden clasificar en dos tipos según cómo codifiquen los diferentes elementos semánticos que caracterizan a un evento de movimiento, especialmente el elemento semántico fundamental, que sería el Camino. Por un lado, estarían las lenguas de marco verbal que lexicalizan el Camino en el verbo principal y la Manera, si es que se menciona, en un elemento aparte. Por otro lado, nos encontraríamos con las lenguas de marco de satélite que siguen el patrón contrario, es decir, el verbo principal codifica la Manera mientras que el Camino se expresa en el satélite. Por ejemplo, en italiano, una lengua de marco verbal, se diría uscire (correndo) ssalir corriendo mientras que en una lengua de marco de satélite como el alemán se utilizaría la construcción heraus rennen >afuera correr^. En el primer grupo de lenguas, además del francés y las lenguas románicas, encontramos también el japonés, el hebreo, el cado, el tamil, el turco, el euskera, las lenguas polinésicas y las mayas, entre otras. En el segundo grupo, además del alemán se incluyen las lenguas germánicas, las eslavas, las fino-úgricas, el ojiwa y el walpiri, entre otras (Strömqvist/Verhoeven 2004).

El análisis tipológico de Talmy ha tenido también una aplicación discursiva interesante, ya que se plantea una visión neorelativista del lenguaje, a partir de la hipótesis del Pensar para hablar de Slobin (1991, 1996, 1997, 2000). Según este autor, el hecho de que una lengua utilice un patrón de lexicalización u otro trae consigo una 
serie de consecuencias relativistas observables en el uso de la lengua. Es decir, que según estemos utilizando una lengua de marco verbal o de satélite, nuestra descripción del evento del movimiento será diferente, ya que, de alguna manera estamos condicionados por las herramientas que nos ofrecen nuestras lenguas. Slobin sugiere que las consecuencias relativistas de su hipótesis se pueden observar en varias tendencias discursivas de los hablantes a la hora de describir un evento de movimiento, especialmente a la descripción de los componentes de Manera y de Camino.

Con respecto al primer componente, las lenguas de marco verbal tienen un léxico de movimiento menos expresivo y numeroso, por lo que, solamente describen la Manera de movimiento si esta información es discursivamente relevante y en los demás casos, la dejan inferida (McNeill 2000, Papafragou e. a. 2006, Özçalışkan/Slobin 2003, Slobin 1996, 1997, 2000). Hasta el momento se han sugerido dos posibles razones para explicar este comportamiento diferente. Por un lado, estas lenguas presentan un repertorio de verbos de Manera más pobre. Por otra parte, también es fundamental la relación entre el esfuerzo cognitivo y el procesamiento de información (Slobin 2006). En las lenguas de marco verbal, como la Manera se expresa fuera del verbo, en un elemento aparte, obliga a que el enunciado sea discursivamente más pesado, lo que requiere a su vez un mayor esfuerzo cognitivo de comprensión por parte de los hablantes, tanto emisores como destinatarios. En relación con el componente de Camino, se dice que las lenguas de marco verbal no suelen ofrecer más información sobre la trayectoria que la contenida en el verbo principal; a lo sumo, pueden utilizar una expresión complementaria para tal fin y, solamente en alguna ocasión excepcional, emplean más de una. Esto hace que la atención narrativa en las lenguas de marco verbal se concentre más en descripciones estáticas del evento y que la dinámica del movimiento se deje implícita.

Tanto los patrones de lexicalización de Talmy como la aplicación discursiva de Slobin se han aplicado al análisis de una amplia gama de lenguas (Strömqvist /Verhoeven 2004), así como desde diferentes perspectivas de análisis lingüístico tanto teórico (Guo e. a. 2009) como aplicado (Cadierno/Robinson 2009, Han/Cadierno 2010). Como cualquier modelo con una cierta repercusión en el ámbito lingüístico, estas teorías han dado lugar a algunas críticas y refinamientos de la teoría (véase IbarretxeAntuñano 2010).

Una de las cuestiones problemáticas que nos interesa para esta investigación es la variación intratipológica, es decir, la variación que existe con respecto a la 
descripción y codificación de los componentes semánticos de los eventos de movimiento en lenguas que pertenecen a un mismo grupo tipológico. Algunos estudios recientes (Ibarretxe-Antuñano 2004a, b, 2009, Slobin 2004, 2006) han demostrado que, aunque las lenguas presenten un mismo patrón de lexicalización, la cantidad y el tipo de información que se ofrece para cada componente semántico no tienen por qué ser la misma. Por ejemplo, aunque el español y el japonés son lenguas de marco verbal, esta última parece >fijarse` algo más en la Manera de movimiento ya que tiene un conjunto de expresiones miméticas muy rico y numeroso que es capaz de lexicalizar una gran variedad de detalles sobre este componente (Sugiyama 2005); y lo mismo puede ocurrir con el componente de Camino, si comparamos la caracterización de este componente entre el español y el euskera, se ve que en la última hay una descripción mucho más detallada y omnipresente del Camino (Ibarretxe-Antuñano 2004a, b). Estas variaciones están estrechamente ligadas a la saliencia o accesibilidad cognitiva que estos componentes semánticos tengan para el hablante. Cuanto más fácil sea la codificación de los mismos, por ejemplo, porque una lengua presente más recursos lingüísticos, más posibilidades hay de que el hablante se fije y los describa en más detalle.

La mayoría de estos estudios sobre la variación intratipológica se han centrado en lenguas que pertenecen a familias (y filos) lingüísticos diferentes. Como resultado se suele dar por hecho que las lenguas con una filiación genética idéntica han de comportarse de forma similar. En este artículo vamos a revisar esta afirmación a partir de un estudio detallado de los eventos de movimiento en tres lenguas románicas: español, italiano y francés, contrastándolas con una lengua de marco de satélite: el alemán. En el caso de las lenguas románicas, los primeros estudios dentro de este modelo sugerían esta posibilidad (véase, por ejemplo, Slobin 2003, 2004). Sin embargo, en los últimos años algunos estudios más detallados sobre lenguas románicas parecen indicar que hay diferencias entre estas lenguas con respecto a la lexicalización de los eventos de movimiento (Berthele 2006, Hijazo-Gascón 2011, Pourcel/Kopecka 2005, Vicario 1997, entre otros).

El objetivo principal de este artículo es doble. Por un lado, queremos comprobar si las lenguas románicas se comportan de forma similar o si existe algún tipo de variación intratipológica con respecto tanto a la Manera como al Camino. Para ello analizaremos estos dos componentes, no solo con respecto a las posibles construcciones que cada lengua ofrece para codificar estos elementos, sino también teniendo en cuenta 
una de las premisas más importantes de la propuesta de Talmy: que las construcciones en las que se basan estas lenguas sean las más >características`, es decir, que sean las que los hablantes utilicen más comúnmente y en contextos discursivos habituales. Esta premisa se olvida a veces en algunos estudios críticos con el modelo talmiano (véase, por ejemplo, Croft e. a. 2010), y se proponen divergencias basadas en construcciones menos comunes $\mathrm{y} / \mathrm{o}$ frecuentes.

Por otro lado, queremos aportar datos empíricos sólidos, que faciliten la confirmación o negación de esta posible variación intratipológica. Hasta ahora la mayoría de los estudios en lenguas románicas, a excepción de los trabajos de Slobin para el español, se han basado en datos fragmentados obtenidos por los investigadores utilizando bien la intuición nativa, bien descripciones de gramáticas, bien diversas herramientas de elicitación que no han sido replicadas en otras lenguas, impidiendo así una comparación contrastiva fiable. En este trabajo, hemos obtenido los datos a partir de la herramienta de la Historia de la Rana (Berman/Slobin 1994).

Este artículo está organizado de la siguiente manera. La Sección 2 resume brevemente los trabajos llevados a cabo sobre los eventos de movimiento en lenguas románicas, especialmente en las tres lenguas de esta investigación: español, francés e italiano. La Sección 3 ofrece un análisis detallado y crítico sobre la descripción de los componentes de Manera (Sección 3.1) y de Camino (Sección 3.2) en estas lenguas. Finalmente, se resumen los resultados obtenidos y se indican futuras líneas de investigación en la sección de las Conclusiones.

\section{Los eventos de movimiento en las lenguas románicas}

En el estudio de los eventos de movimiento dentro del marco teórico que nos ocupa, se suele dar por hecho que la familia románica pertenece a las lenguas de marco verbal. Es posible que una de las razones principales sea que el español es la lengua que se toma como modelo en estos trabajos y, dada su clara pertenencia a las lenguas de este grupo, su filiación se extienda al resto de las lenguas románicas. Estudios clásicos como los de Slobin $(2003,2004)$ califican al francés, al gallego, al italiano o al portugués como lenguas de marco verbal.

Sin embargo, en los últimos años algunos estudios más detallados sobre lenguas románicas parecen indicar que estas no son tan homogéneas. En parte estas diferencias parecen fundamentarse en la distinta evolución de las lenguas románicas, ya que al 
mismo tiempo que el latín se está fragmentando dando lugar a los nuevos romances, también se está produciendo un cambio tipológico: de lengua de marco satélite a lengua de marco verbal. Hay varios ejemplos que ilustran este cambio progresivo de patrón de lexicalización: la pérdida del contenido semántico de los casos y su posterior eliminación que da lugar al sistema preposicional románico (Ferrari/Mosca 2010), la pérdida de transparencia y productividad del sistema prefijal latino que hace que los satélites de Camino (p. ej. in- en inire) se lexicalicen en la raíz verbal y se reinterpreten como monomorfemáticos (p. ej. entrar) o la tendencia a crear verbos denominales sobre una base con direccionalidad interna (p. ej. mons, -tis >montaña $>>*_{\text {montare }}>$ Cat. muntar >subir`) que sustituye al patrón de lexicalización latino por el actual románico con el Camino en el verbo (Slotova 2008). Repasemos ahora brevemente algunos de los aspectos más importantes sobre las tres lenguas de nuestro análisis.

El español se ha considerado como una lengua de marco verbal típica (Talmy 1985, 1991, 2000, Slobin 1991, 1996, 1997, 2004, Sebastián/Slobin 1994). Como tal, los verbos de movimiento ${ }^{1}$ en español codifican mayoritariamente el Camino (subir, salir), aunque también expresan en menor medida la Base (aterrizar, alunizar) y la Manera (correr, volar). Estos últimos suelen ser, no obstante, verbos semánticamente muy generales que no ofrecen excesivos detalles sobre la forma en la que se lleva a cabo el movimiento más allá del patrón motriz y que requerirían otros elementos complementarios (deprisa, con mucha calma) para ser más específicos. Normalmente, en una descripción de movimiento, la función de verbo principal en español suele estar desempeñada por un verbo de Camino (salió de casa), aunque también puede ocupar este puesto uno de Manera siempre que no infrinja la "restricción del cruce del límite" (Aske 1989, Slobin/Hoiting 1994), es decir, siempre que no entre en conflicto con aquellos casos en los que se atraviesa un límite espacial, en cuyo caso se ha de utilizar obligatoriamente un verbo que marque la trayectoria (corrió a casa vs. salió de la casa corriendo vs. *? corrió a afuera de la casa) (véase Gennari e. a. 2002, Naigles e. a. 1998).

Respecto a la Manera de movimiento, generalmente no suele expresarse en las descripciones de movimiento, a no ser que sea discursivamente relevante. Respecto al Camino, no se suele especificar el origen y la meta del movimiento en complementos

\footnotetext{
${ }^{1}$ Los verbos de movimiento han sido ampliamente estudiados en esta lengua, fundamentalmente en relación con la intransitividad y la inacusatividad (Alcina y Blecua 1975, Cifuentes Honrubia 1999, Mendikoetxea 1999, RAE 2009), desde el marco teórico de la semántica léxica de Jackendoff (Morimoto 2001), y desde la perspectiva de la tipología de Talmy (Cifuentes-Férez 2010).
} 
dependientes de un mismo verbo, sino que la tendencia es a utilizar solo uno de los dos. No se trata de una restricción gramatical de la lengua, sino de una tendencia discursiva de los hablantes. Sin embargo, esta no es la tendencia general de la lengua, o queda reservada a registros más cultos. Los hablantes de español utilizan otros medios de expresar el Camino: no codifican cada segmento de este componente, dejando que se infiera a partir de las descripciones de la escena y el uso de verbos de movimiento direccionales que implican un cambio de localización (Sebastián/Slobin 1994), o utilizan elementos alternativos como las construcciones de relativo (Slobin 1996).

El italiano es quizá la lengua románica más polémica respecto a su posición en la tipología, principalmente debido a la existencia de los verbos analíticos o sintagmáticos, también llamados construcciones verbo-partícula, compuestos de una base verbal y una partícula o adverbio.

Estos verbos con partícula han hecho que varios autores (Cardini 2008, Cini 2008, Iacobini/Masini 2007a, b, Masini 2005, 2008, Schwarze 1985, Spreafico 2008a, b) sostengan que el italiano, además de tener el patrón de lexicalización típico de las lenguas románicas (uscire >salir $<$ ), también muestre casos de construcciones del grupo de lenguas de marco de satélite (scivolare >resbalar`via >fuera<). Schwarze (1985), por ejemplo, sugiere que el italiano tiene tres tipos de conflación léxica: (a) El tipo románico (el Camino en el verbo), (b) El Movimiento y la prospectiva (Deixis) en el verbo (venire >venir $\iota)^{2}$ y (c) el tipo germánico (la Manera en el verbo con partículas). Iacobini/Masini (2007b: 161) consideran que la función primaria de las partículas italianas parece ser el de añadir valores direccionales a la raíz verbal, así pues funcionan como verdaderos satélites. Otros autores como Simone (2008) llegan incluso a clasificar al italiano como una lengua de marco de satélite.

Otro punto interesante con respecto a estas construcciones de verbo+partícula en italiano es su origen. Algunos autores (Schwarze 1985, Simone 1996 y, en el caso del friulano, Vicario 1997) inicialmente consideraban estos verbos sintagmáticos como el resultado de una situación de contacto con el alemán, ya que este tipo de construcciones, típicas del discurso oral, eran ajenas a la herencia toscana y habían entrado en el italiano a partir de los dialectos septentrionales. Sin embargo, a partir de estos primeros trabajos, el estudio de los verbos sintagmáticos se ha desarrollado ampliamente tanto desde el

\footnotetext{
${ }^{2}$ A este segundo tipo se le pueden hacer dos objeciones desde la perspectiva talmiana. Por un lado, el verbo andaré >ir suele clasificarse como neutro, no como verbo deíctico, y por otra parte más importante, la información deíctica en el modelo talmiano es parte integral del Camino, por lo que no se consideraría un grupo diferente.
} 
punto de vista diacrónico (Amenta 2008, Iacobini 2009, Masini 2005) como diatópico (dialecto siciliano- italiano regional de Sicilia, Amenta 2008; trentino, Cordin 2008; bergamasco, Bernini 2008, Spreafico 2008a, b), solo para descubrir que estas estructuras parecen ser propias de la lengua italiana y encontrarse en diversas variedades de la lengua. Actualmente se considera que la aparición de las construcciones verbopartícula es intrínseca a la evolución de la lengua italiana, como consecuencia la pérdida de prefijos y casos del latín tardío (Iacobini 2009, Iacobini/Masini 2007a, b, Masini 2005, Schwarze 2008).

Una cuestión que queda pendiente en la mayoría de estos trabajos, sin embargo, y que vamos a intentar resolver en este artículo, es el uso real de este tipo de construcciones satelitales por parte de los hablantes italianos. Como ya hemos comentado anteriormente, una parte fundamental de la teoría de Talmy es precisamente el uso característico y no todo el inventario de posibles construcciones de una lengua. Este tipo de construcciones italianas es una de las características que diferencia el italiano de otras lenguas románicas, pero es necesario comprobar al menos dos cuestiones. Por un lado, si realmente son parte habitual del discurso nativo como para considerar el italiano una lengua con dos patrones de lexicalización (o perteneciente a otro grupo), y por otra, si realmente estas partículas son satélites comparables a los de otras lenguas como, por ejemplo, el alemán.

Respecto a la expresión de la Manera, Baicchi (2005), partiendo de la posibilidad de uso de las construcciones de verbo+partícula en traducciones del inglés al italiano y al español, considera que el italiano estaría en una posición más intermedia que el español en la escala de saliencia de la Manera, debido a razones históricas. Sin embargo, estudios como el de Cardini (2008) refutan estas conclusiones. A partir tanto del inventario de verbos de Manera recabados en diccionarios como de datos experimentales (de disponibilidad léxica y narraciones de la historia de la rana), Cardini afirma que el italiano es una lengua de saliencia de Manera baja como el resto de las lenguas románicas. .

En líneas generales, el francés se ha clasificado como una lengua de marco verbal $^{3}$ (Berthele 2004, 2006, Gullberg e. a. 2008, Hendriks e. a. 2008, Hickmann 2006, 2007, Hickmann/Hendriks 2006, 2010, Hickmann e. a. 2009, Khalifa 2001,

\footnotetext{
${ }^{3}$ Los trabajos de Bally (1965), Tésniere (1959) ya consideraban al francés como una lengua con unas estructuras diferentes a lenguas como el alemán en este campo semántico, diferenciando entre verbos de desplazamiento y verbos de movimiento.
} 
Ochsenbauer 2010, Slobin 2003, 2004), ya que no presenta elementos tan conflictivos o propios como los verbos sintagmáticos del italiano. Algunos autores, sin embargo, han propuesto que podría clasificarse el francés como una lengua "híbrida", ya que hay casos en los que el verbo de Manera ejerce de verbo principal (rouler >rodar $`$ ) y verbos que codifican a la vez los componentes de Camino y Manera (grimper strepar`, dévaler >bajar rodando<) (Pourcel/Kopecka 2005). Porquier (2001, 2003), por ejemplo, también considera que el francés tiene algunas construcciones más >satelitales` ya que utiliza, especialmente en el lenguaje oral no normativo, ciertos adverbios direccionales con verbos de Manera (il court dehors >corre fuera২). Estos adverbios, además de ser comunes en otras lenguas románicas, tampoco se podrían clasificar sintácticamente como satélites según la definición de Talmy y equivaler, como ya reconoce el autor, a los verbos frasales ingleses. Kopecka (2004, 2006, 2009, en prensa) se ha centrado también en la posibilidad de que el francés presente rasgos de las lenguas de marco de satélite a partir del uso de prefijos, que como veíamos anteriormente eran característicos del latín. En un principio, el hecho de que el francés mantenga la posibilidad de utilizar prefijos con verbos de movimiento permite a Kopecka afirmar que el francés es una lengua >híbrida<; sin embargo, la poca productividad morfológica de estos prefijos (Kopecka 2004: 194), junto a su relativa transparencia semántica con diferentes grados de opacidad (Kopecka 2006:5) no sustenta esta afirmación. Aunque el uso de estos prefijos era más común en francés medieval y clásico (Kopecka en prensa), la productividad de los mismos en francés actual es escasa y se mantiene solamente en dos prefijos: dé(s)- >cambio de estado< (décrocher >despegar`) y re->iteratividad ( repartir >volver a partir $<$ ).

El problema de todas estas afirmaciones es que, por un lado, estas características que se utilizan como propias del francés también aparecen en otras lenguas románicas (grimper y trepar, courrir dehors y correr fuera), y que, por otro, al igual que ocurría con el italiano, faltan trabajos empíricos que realmente prueben que, por ejemplo, estos prefijos franceses, que podrían utilizarse como satélites de Camino, se utilizan habitualmente en descripciones cotidianas del movimiento y que contrasten el uso con otras lenguas románicas. Algo que en este artículo intentaremos subsanar.

Con respecto a la descripción de la Manera, no hay trabajos exhaustivos que se dediquen a este componente, a excepción de algunos relacionados con la adquisición de primera y segunda lenguas. El francés, como es característico de las lenguas de marco verbal, generalmente omite la información sobre este componente. Hickmann (2007) 
señala, por ejemplo, que no suele estar presente en las descripciones de movimiento de niños. Si se expresa, aunque hay verbos de Manera también, suele ser a través de enunciados secundarios, oraciones subordinadas, gerundios, etc. Hickmann e. a. (2009) afirman que en estos casos, la Manera se utiliza en localizaciones generales, sin indicar cambios de localización, que se infieren del contexto.

\section{La Manera y el Camino en tres lenguas románicas}

Tras este breve repaso por algunas de las características más importantes de los eventos de movimiento en el español, el italiano y el francés, en esta sección llevaremos a cabo el análisis de dos de los componentes semánticos del movimiento en la tipología talmiana: la Manera y el Camino. Para ello, y dado que uno de los objetivos de este trabajo es comprobar si existen diferencias intratipológicas entre estas lenguas basándonos en el uso prototípico que los hablantes hacen de las construcciones de movimiento, seguiremos el análisis propuesto por Slobin $(1991,1996,2004)$ en su hipótesis del pensar para hablar.

Como ya hemos mencionado en la sección 1 , los datos han sido obtenidos utilizando la herramienta de las historias de la rana (Berman/Slobin 1994). Este estímulo consiste en la narración oral por parte de los informantes de lo que ocurre en un libro de imágenes que cuenta la historia de un niño que pierde a su rana y va a buscarla por el bosque. A pesar de las posibles limitaciones que puede suponer un estímulo semidirigido como el que utilizamos, las ventajas para nuestros objetivos son claras. Los datos se recogen siguiendo la misma metodología y por lo tanto, se pueden contrastar, y así aportar evidencia empírica con respecto a algunas cuestiones abiertas que perfilábamos en la sección anterior: si son todas lenguas de marco verbal y si existen diferencias intratipológicas. Para cada lengua hemos utilizado doce hablantes nativos adultos como viene siendo habitual en esta metodología (con una edad media de 21,58 los españoles, 23,91 los alemanes, 21,67 los franceses y 21,58 los italianos). Además, y para poder ver en perspectiva las descripciones de los eventos de movimiento de estas lenguas de marco verbal con respecto a la tipología de Talmy, hemos incluido datos de una lengua de marco de satélite, el alemán (véase Bamberg 1994, Berthele 2004, 2006, Hijazo-Gascón 2011, Ochsenbauer 2010, para una descripción del alemán en este modelo teórico). Los datos también se han recogido a 
través de la descripción oral de las historias de la rana por parte de doce hablantes nativos. Empezaremos con el componente de Manera.

\subsection{La Manera en lenguas románicas}

La expresión de la Manera en los eventos de movimiento en las lenguas de marco verbal no suele ser muy detallada o frecuente si se compara con la de las lenguas de marco de satélite. Según la caracterización de este grupo (Slobin 1996, 2004), los hablantes no suelen prestar atención al componente de Manera y, a no ser que sea discursivamente relevante, no se suele mencionar.

Veamos cómo se cumple esta caracterización en las tres lenguas románicas de este estudio y en alemán, que nos va a servir para contrastarlas con una lengua de marco satélite y de otra familia.

El primer paso que vamos a dar es contabilizar la expresión de la Manera a partir del inventario de verbos que describen este elemento. Las tablas 1 y 2 recogen los datos obtenidos.

\begin{tabular}{|l|l|lr|l|l|l|}
\hline Lenguas & $\begin{array}{l}\text { Total tipos } \\
\text { de verbos }\end{array}$ & $\begin{array}{l}\text { Tipos de } \\
\text { verbos } \\
\text { Manera }\end{array}$ & $\begin{array}{l}\text { Ocurrencias } \\
\text { verbos } \\
\text { Manera }\end{array}$ & $\begin{array}{l}\text { Media verbos } \\
\text { de Mn / } \\
\text { hablante }\end{array}$ & $\begin{array}{l}\% \text { verbos } \\
\text { de Mn }\end{array}$ \\
\hline Español & 39 & 7 & 11 & 0,92 & $5,88 \%$ \\
\hline Italiano & 60 & 10 & 16 & 1,34 & $7,62 \%$ \\
\hline Francés & 53 & 3 & 14 & 1,17 & $6,23 \%$ \\
\hline Alemán & 67 & 23 & 62 & 5,16 & $29,11 \%$ \\
\hline
\end{tabular}

Tabla 1: Verbos de Manera

\begin{tabular}{|c|c|}
\hline Lenguas & Tipos y ocurrencias de los verbos de Manera \\
\hline $\begin{array}{l}\text { Español } \\
\text { (7) }\end{array}$ & $\begin{array}{l}\text { correr (5), lanzarse (1), empujar (1), pasear (1), pegar un salto (1), saltar (1) } \\
\text { y tropezarse (1). }\end{array}$ \\
\hline $\begin{array}{l}\text { Italiano } \\
(10)\end{array}$ & 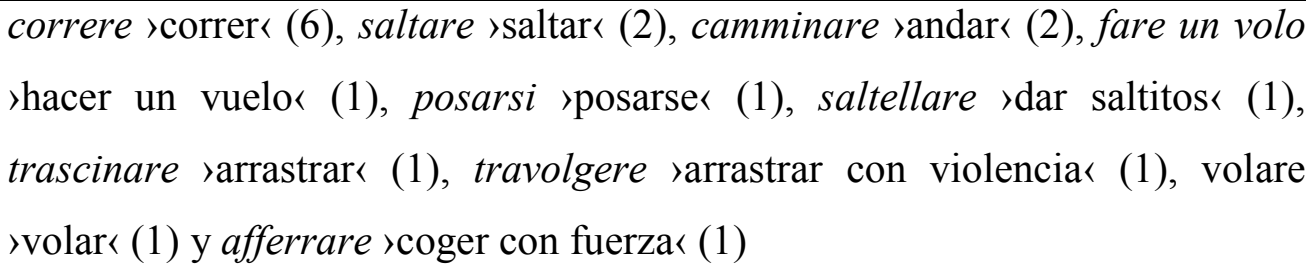 \\
\hline
\end{tabular}




\begin{tabular}{|c|c|}
\hline $\begin{array}{l}\text { Francés } \\
\text { (3) }\end{array}$ & courir >correr $<$ (11), secouer >agitar $<$ (2) y filer >irse pitando < (1) \\
\hline $\begin{array}{l}\text { Alemán } \\
\text { (23) }\end{array}$ & 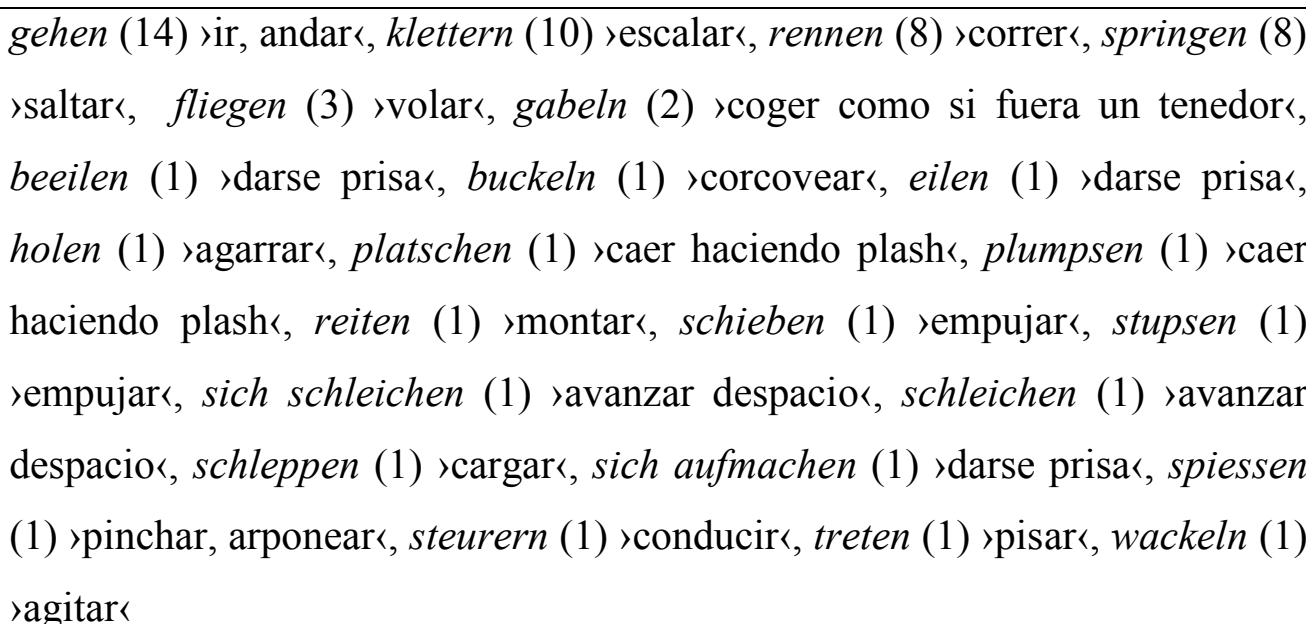 \\
\hline
\end{tabular}

Tabla 2: Tipos y ocurrencias de los Verbos de Manera

Como se puede observar en la Tabla 1, el número total de verbos de Manera es escaso. El francés es la lengua con menos verbos diferentes de Manera, solamente tres, mientras que el italiano que es la que muestra un mayor número con diez tipos. Aun así, las tres lenguas están lejos de los 23 tipos que se usan en el alemán. Al realizar el análisis estadístico con pruebas no paramétricas ${ }^{4}$, nos encontramos con un valor de $p=, 001$ en el Kruskal-Wallis (KW), lo que nos indica una diferencia significativa al comparar los cuatro grupos. Tras realizar la prueba de Mann-Whitney (MW), vemos que, como cabe esperar la utilización de estos verbos por parte de los hablantes nativos románicos no hay diferencias significativas entre estos grupos (MW, español-italiano $\mathrm{p}=, 582$, español-francés $\mathrm{p}=, 843$, francés-italiano $\mathrm{p}=, 539)$, y sí entre el alemán y cada una de las lenguas románicas (MW, todas $\mathrm{p}=, 000)$. Con respecto al contenido semántico, los verbos que más se utilizan en estas tres lenguas son generales, tal y como predice la teoría. Los verbos correr, correre y courir son los que más ocurrencias reciben. No obstante cabe destacar la utilización de algunos verbos más ricos semánticamente como filer >irse pitando < en francés o travolgere >arrastrar con violencia en italiano, que

\footnotetext{
${ }^{4}$ Las pruebas estadísticas realizadas son no paramétricas (Kruskal-Wallis para la comparación intergrupal y Mann-Whitney para comparar los grupos dos a dos), ya que al tratarse de una tarea de producción libre no asumimos que la distribución de los datos sea normal. Por lo tanto utilizamos pruebas más restrictivas, en las que es más complicado observar diferencias significativas. En los casos en los que hemos encontrado valores atípicos, hemos retirado esos valores y hemos repetido el análisis. Presentamos en el artículo los resultados finales, libres de valores atípicos. El nivel $\alpha$ es de $p<, 050$ para Kruskal-Wallis y de $p<, 025$ para Mann-Whitney.
} 
funcionan como hipónimos de verbos generales como courir y trascinare respectivamente, aunque no son frecuentes, ya que solo cuentan con una ocurrencia.

El siguiente paso sería analizar si los hablantes románicos utilizan otros medios lingüísticos además del verbo para la expresión de la Manera ${ }^{5}$, para compensar la falta de verbos principales, propia del patrón de lexicalización de marco verbal. La tabla 3 resume los resultados obtenidos.

\begin{tabular}{|c|c|}
\hline & ipos y ocurrencias de elementos de Manera \\
\hline $\begin{array}{l}\text { Español } \\
\text { (15) }\end{array}$ & $\begin{array}{l}\text { sintagmas adjetivos: asustado (3), cabreado (1), camuflado (1), grande } \\
(1), \text { muy asustado (1), preocupado }(1), \text { todo contento }(1) \\
\text { sintagmas adverbiales: perfectamente }(1) \\
\text { sintagmas preposicionales: de cabeza }(1), \text { de repente }(1) \\
\text { participios: enganchado }(1), \text { montado }(1) \\
\text { gerundios: corriendo }(3), \text { correteando }(3), \text { volando }(1)\end{array}$ \\
\hline $\begin{array}{l}\text { Italiano } \\
(12)\end{array}$ & 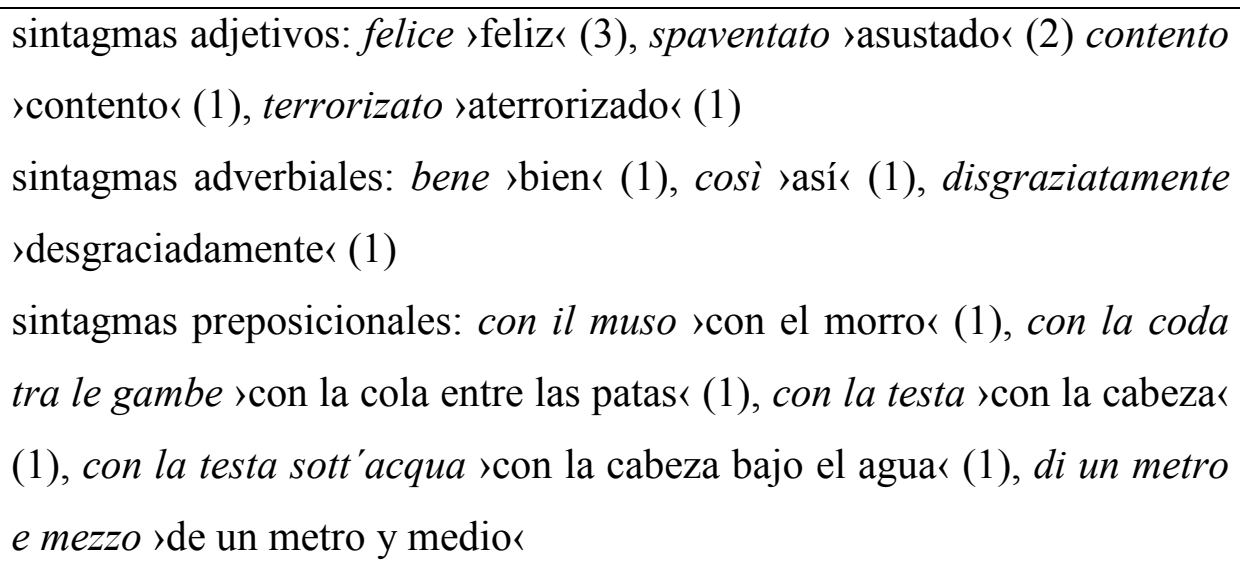 \\
\hline $\begin{array}{l}\text { Francés } \\
\text { (13) }\end{array}$ & 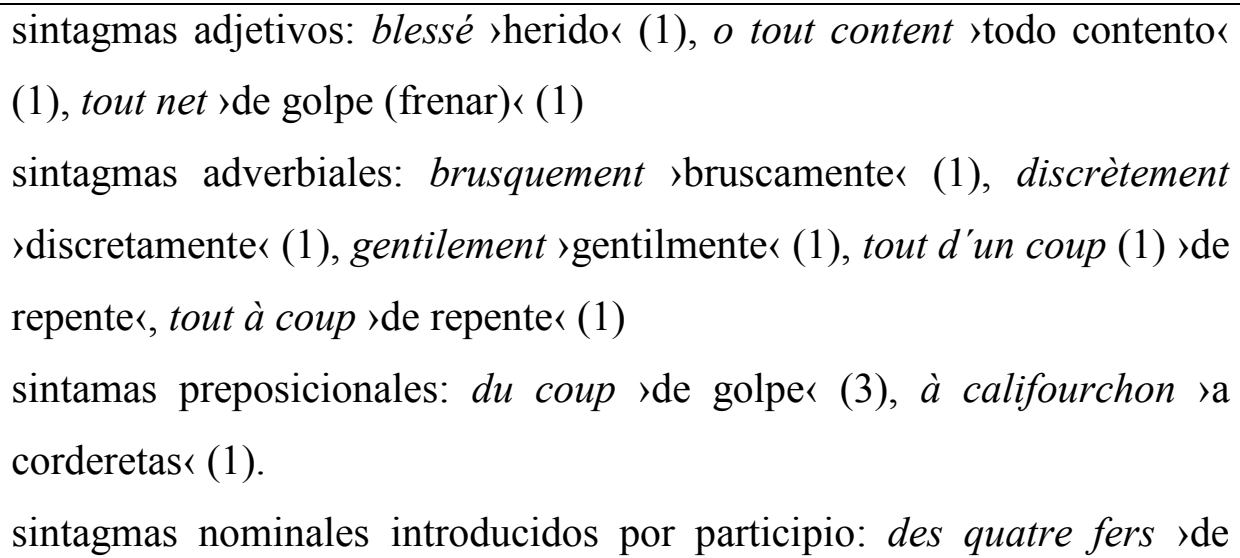 \\
\hline
\end{tabular}

\footnotetext{
${ }^{5}$ En este trabajo agrupamos bajo la etiqueta de Manera cualquier descripción que indique la forma en la que se lleva a cabo el movimiento, sin entrar en subclasificaciones como patrón motriz (correteando, en courant >corriendo<), estado psicológico (spaventato >asustado<), etc. (para un análisis de los subtipos de Manera véanse Cifuentes-Férez 2010, Ibarretxe-Antuñano 2006, Özçalişkan 2004, Slobin 2000).
} 


\begin{tabular}{|c|c|}
\hline & $\begin{array}{l}\text { golpe (frenar) } \\
\text { participios: accroché >enganchado }<\text { (1) } \\
\text { gerundios introducidos por preposición: en courant }>\text { corriendo }<\text { (3) }\end{array}$ \\
\hline $\begin{array}{l}\text { Alemán } \\
\text { (11) }\end{array}$ & 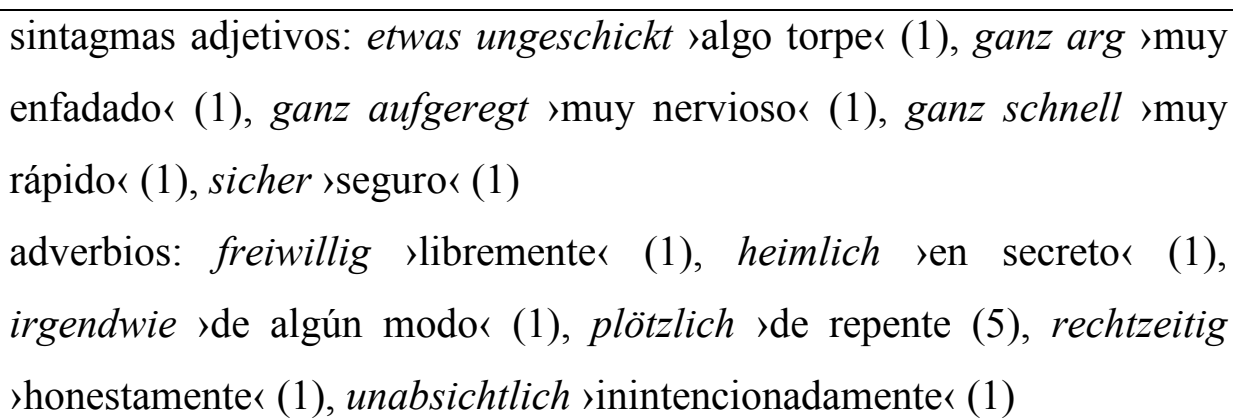 \\
\hline
\end{tabular}

Tabla 3: Expresiones complementarias de Manera. Tipos y ocurrencias.

Según los datos de la Tabla 3, la Manera también se describe fuera del verbo por medio de diferentes estructuras sintagmáticas como las adjetivas (asustado), las adverbiales (tout d'un coup) o las preposicionales (con la testa sott'acqua), además de gerundios y participios en francés (en courant, accroché) y en español (corriendo, montado). Sin embargo, estas descripciones extraverbales no son muy numerosas en las lenguas romances y vienen a confirmar los resultados anteriores. Al llevar a cabo el análisis estadístico $(\mathrm{KW}, \mathrm{p}=, 000)$, vemos que el grupo de los alemanes es el que difiere de las lenguas romances ( $\mathrm{MW}, \mathrm{p}=, 000$ en los tres casos). Las lenguas romances no muestran diferencias significativas entre sí (MW, español-italiano: $p=, 880$, español-francés: $p=$ ,651, italiano-francés: $\mathrm{p}=, 847$.

De estos datos se desprenden dos conclusiones con respecto al componente de Manera. En primer lugar, el español, el francés y el italiano se comportan como lenguas típicamente de marco verbal con una descripción escasa de este componente. Es más, si revisamos una de las escenas que ha servido a autores como Slobin (2004) para confirmar el uso escaso de la Manera en este grupo, la escena del búho, ninguno de los hablantes románicos utiliza un verbo de Manera, sino verbos de Camino: en español salir (5); en italiano uscire >salir (6) y venire (fuori) >venir (fuera) (1); y en francés sortir >salir< $(8)^{6}$. En segundo lugar, no hay variación intratipológica con respecto al componente de Manera entre estas tres lenguas.

\footnotetext{
${ }^{6}$ La escena del búho se refiere al momento en el que se muestra la salida volando de un búho del agujero de un árbol. Los números entre paréntesis indican el número de ocurrencias. Al ser una narración libre no todos los sujetos han mencionado esta escena en sus descripciones, de ahí que el número total no sea doce.
} 


\subsection{El Camino en lenguas románicas}

El Camino es el componente fundamental de un evento de movimiento, y por lo tanto, ha de mencionarse. Sin embargo, las descripciones del movimiento difieren en la cantidad de información que contienen sobre este elemento. Los hablantes de lenguas de marco verbal, al contrario que los del grupo de lenguas de marco de satélite, suelen ofrecer pocos detalles. Normalmente, la información sobre el Camino se encuentra codificada en el verbo principal, y a lo sumo en un elemento complementario. Estas descripciones suelen ser más estáticas, ya que dan detalles sobre el entorno pero suelen inferir las trayectorias que siguen las Figuras.

A pesar de esta caracterización general de las lenguas de marco verbal, hay estudios que demuestran que algunas lenguas de este grupo no se comportan así. En euskera, por ejemplo, Ibarretxe-Antuñano (2004a) muestra que las caracterizaciones del Camino son tan complejas con respecto a la cantidad de información como cualquier lengua de marco de satélite. Arguye que, entre otras, ciertas características morfosintácticas de esta lengua como la riqueza de sistema lingüístico espacial (casos, postposiciones), el orden SOV, la omisión verbal (elipsis total y parcial) y los verbos soporte facilitan a que se comporte como una lengua de saliencia alta de Camino (Ibarretxe-Antuñano 2004b).

Aunque la estructura de las lenguas románicas para la descripción del movimiento puede ser similar, como hemos descrito en la sección 2, existen algunas particularidades morfosintácticas que podrían tener consecuencias para la descripción del componente de Camino. Los prefijos franceses y los verbos sintagmáticos italianos podrían facilitar que este componente se describiera más en estas lenguas en contraste con el español, y así hacer que surgieran diferencias intratipológicas. Para comprobar esta posibilidad, vamos a analizar el componente de Camino.

Siguiendo la metodología de Slobin (1996), vamos a iniciar este análisis utilizando la distinción entre verbos-menos-base y verbos-más-base. Los primeros se refieren a las construcciones que solamente contienen un verbo principal como en (1) o un verbo principal más satélite ${ }^{7}$ como en (2) y los segundos a las construcciones que

\footnotetext{
${ }^{7}$ Slobin (1996), tras analizar la diferencia de uso entre los verbos escuetos (sin ningún satélite) y los verbos con satélite del inglés y del español decide abandonar este tipo de análisis ya que puede dar una imagen distorsionada de la descripción del movimiento en estas lenguas. Una construcción con el verbo principal caer en español equivale a una construcción con un verbo+satélite en inglés fall down; por lo
} 
cuentan con un verbo de movimiento principal o un verbo principal (más satélite) y algún elemento de Camino adicional como en (3).

(1) Und ja dieses fällt dann

y sí este cae entonces

$>\mathrm{Y}$ entonces este se cae $<$ [12de]

(2) Und der Wespenstock fällt dann runter

y el panal cae entonces abajo

\Y el panal entonces se cae < [06de]

(3) Der Junge in das Wasser hineinfällt

el chico en el agua ahí.abajo.cae

$>$ El chico se cae al aguar [03de]

En las lenguas románicas, al ser lenguas de marco verbal, se van a encontrar más construcciones de verbo-menos-base. Hay que recordar una vez más, que en este modelo siempre estamos trabajando con aquellas estructuras que son características a la hora de describir el movimiento. En otras palabras, también se pueden utilizar las construcciones de verbo-más-base, pero no van a ser igual de frecuentes si las comparamos con las de verbo-menos-base o con la descripción del movimiento de las lenguas del otro grupo tipológico (p. ej., el alemán).

Otra diferencia importante que también comentaremos más adelante se refiere al número de elementos adicionales del Camino que se mencionan en estas descripciones. Las lenguas de marco verbal suelen ceñirse a un solo elemento, mientras que las lenguas de marco de satélite suelen mostrar una gran profusión de elementos adicionales como vemos en (4).

(4) Fällt dieses von dem Ast herunter auf den Boden

cae este de el rama hacia.aquí.abajo a el suelo

〉Este cae de la rama al suelo aquí abajo< [12de] 
En (4) además de utilizarse el satélite herunter, compuesto en realidad por dos: el deíctico her- >hacia aquí< y el satélite unter >abajo<, se añaden dos elementos de Base: uno de origen (von dem Ast >de la rama $)$ y uno de meta (auf dem Boden >al suelo<).

Pasemos a analizar primeramente las construcciones de verbos menos- y másbase que aparecen en toda la narración de las Historias de la rana. La Tabla 4 resume los resultados obtenidos en las tres lenguas románicas y el alemán.

\begin{tabular}{|l|l|l|l|l|l|l|l|}
\hline Lenguas & $\begin{array}{l}\text { Verbos de } \\
\text { Movimiento }\end{array}$ & $\begin{array}{l}\text { Menos } \\
\text { Base }\end{array}$ & $\begin{array}{l}\text { Media } \\
\text { Menos } \\
\text { Base }\end{array}$ & $\begin{array}{l}\text { Menos } \\
\text { Base }\end{array}$ & $\begin{array}{l}\text { Más } \\
\text { Base }\end{array}$ & $\begin{array}{l}\text { Media } \\
\text { Más } \\
\text { Base }\end{array}$ & $\begin{array}{l}\% \text { Más } \\
\text { Base }\end{array}$ \\
\hline Español & 195 & 95 & 7,92 & $48,78 \%$ & 100 & 8,33 & $51,28 \%$ \\
\hline Italiano & 210 & 69 & 5,75 & $32,86 \%$ & 141 & 11,75 & $67,14 \%$ \\
\hline Francés & 225 & 126 & 10,5 & $56 \% \%$ & 99 & 8,25 & $44 \%$ \\
\hline Alemán & 213 & 83 & 6,92 & $38,97 \%$ & 130 & 10,83 & $61,03 \%$ \\
\hline
\end{tabular}

Tabla 4: Construcciones de verbo-menos-base y verbo-más-base

Según los datos de la Tabla 4, de entre las lenguas románicas, los hablantes de italiano son los que describen el Camino en más detalle con un total de 141 casos, lo que supone un $67,14 \%$ y una media de 11,75 casos por hablante. Al italiano le sigue el español con 100 casos $(51,28 \%)$ y finalmente, el francés, que con 99 casos $(44 \%)$, es la única lengua que muestra una preferencia por los verbos-menos-base. El alemán, a pesar de ser una lengua de marco de satélite, presenta menos casos que el italiano (130, 61,03\%), aunque hay que tener en cuenta que en este análisis el uso de verbos y satélites, muy frecuente y rico en alemán, se incluye en la categoría de verbos-menos-base.

Como cabía esperar según la teoría, en el análisis estadístico $(\mathrm{KW}, \mathrm{p}=, 004)$, el alemán presenta una tendencia estadística tanto con los hablantes de español $(\mathrm{MW}, \mathrm{p}=$ ,069) como con los hablantes de francés ( $\mathrm{MW}, \mathrm{p}=, 100)$, y entre estos dos últimos no hay diferencia significativa ( $\mathrm{MW}, \mathrm{p}=, 651)$. Sin embargo, los datos estadísticos referentes al italiano arrojan unos resultados interesantes. Por un lado, con respecto al alemán se observa una tendencia ( $\mathrm{MW}, \mathrm{p}=, 068)$, pero lo que verdaderamente nos interesa es que se da una diferencia significativa entre los hablantes de italiano y español (MW, $p=, 000)$ y entre los hablantes de italiano y francés $(M W, p=, 008)$. Es decir, nos encontramos con una diferencia intratipológica dentro de las lenguas 
románicas: el italiano se diferencia significativamente del francés y del español con respecto a la descripción del Camino.

A continuación vamos a examinar los casos de verbos-más-base con más de un elemento. Los datos de alemán cumplen con lo esperado; tenemos ocho casos de verbos-más-base, algunos tan complejos y con elementos reiterativos de Camino como el ejemplo de (5), en el que todos, incluido el verbo principal, describen la trayectoria descendente.

und die beiden nach unten fielen den Abrund hinunter in einen Teich y los ambos hacia abajo caen el precipicio allí.abajo en un estanque >y los dos cayeron hacia abajo por el precipicio allí abajo a un estanque ‘ [08de]

En los datos de los hablantes de las lenguas románicas, estas expectativas se cumplen en el caso del español y el francés, ya que no encontramos ningún caso con más de un elemento. Sin embargo, una vez más, el italiano se comporta de una manera totalmente distinta, ya que hay doce casos de verbos-más-base con dos e incluso tres elementos, 10 y 2 respectivamente). En algunas ocasiones, se utilizan enunciados con dos elementos de Base realizados por sendos sintagmas preposicionales como en (6):

(6) da una parte un po' più alta cade in basso de una parte un poco más alta cae en bajo >De una parte un poco más alta cae a la parte baja [04it]

En otras ocasiones, los enunciados contienen dos piezas de información, un sintagma preposicional y un adverbio direccional como en (7):

$$
\begin{aligned}
& \text { Però cade giù dalla finestra } \\
& \text { sin.embargo cae abajo de.la ventana } \\
& \text { >Sin embargo, cae (abajo) de la ventana [05it] }
\end{aligned}
$$

También hay enunciados más complejos con tres elementos, dos sintagmas preposicionales y un adverbio direccional como en (8):

$$
\text { fa cadere il bambino e il cane giù da un dirupo su un lago }
$$


hace caer el niño y el perro abajo desde un precipicio sobre un lago $>$ hace caer abajo al niño y al perro desde un precipicio hasta un lago< [03it]

Los resultados que acabamos de analizar sobre la descripción del Camino ponen de manifiesto que existen diferencias intratipológicas en este grupo entre el italiano y las otras dos lenguas románicas analizadas, el español y el francés. El siguiente paso sería preguntarse por las causas que expliquen el porqué de estas diferencias. Otros trabajos sobre variación intratipológica han sugerido que uno de los factores para explicar estos comportamientos divergentes pueden ser los recursos lingüísticos que las lenguas tienen (cf. Ibarretxe-Antuñano 2004b). Como comentábamos en la sección 2, el italiano cuenta con los verbos sintagmáticos como rasgo diferenciador con respecto a las otras dos lenguas. Tenemos el elemento giù >abajo junto al verbo (fare) cadere >(hacer) caer « en (7) y (8), pero hay más combinaciones posibles en los datos analizados. Encontramos los siguientes tipos (entre paréntesis las ocurrencias): andare via >irse de un sitio (1), andarsene via >irse de un sitio (1), portare via >llevarse de un sitio< (2), portarsi via >llevarse de un sitio< (1), trascinare via >llevarse arrastrando de un sitio< (1), uscire fuori >salir fuera (3), venire fuori >venir fuera, salir $<$ (2), saltare fuori $>$ saltar fuera〈 (3), buttarsi giù >tirarse abajo< (1), cadere giù >caer abajo< (1), fare cadere giù >hacer caer abajo< (1), correre dietro >correr detrás, perseguir corriendo〈(1). Por lo tanto, es posible argumentar que los recursos lingüísticos de una lengua sí que ayudan a que se describa un elemento semántico en más detalle.

Ahora bien, este tipo de estructuras en las que el verbo se combina con un adverbio direccional (tal y como se describe en las gramáticas tradicionales) no es exclusiva del italiano. De hecho, en los datos de español tenemos cuatro ejemplos: caer(se) abajo (2) y salir (a)fuera (2) y en los de francés, un ejemplo: courir après >correr detrás $\measuredangle$ Sin embargo, la versatilidad y facilidad de combinación que se da en el italiano no se permite en las otras dos lenguas románicas (p. ej., via >fueraく, que además no tiene un equivalente en español ni francés), lo cual puede explicar la mayor descripción del Camino en esta lengua.

También comentábamos arriba que algunos autores (Poucel/Kopecka 2005) adjudicaban al francés una posición híbrida en la tipología de Talmy, especialmente por la existencia de prefijos verbales que describían trayectorias. Los datos que hemos analizado contradicen tajantemente estas hipótesis. Los hablantes franceses apenas 
utilizan estos prefijos mara señalar el Camino; es más, como hemos visto, son los que menos atención prestan a este componente, por detrás de los hablantes españoles.

4. Conclusiones: ¿existe variación intratipológica en las lenguas románicas?

Al inicio de este trabajo nos planteábamos dos objetivos: averiguar si existe variación intratipológica en las lenguas románicas y aportar datos empíricos que sustenten o desestimen la propia variación intratipológica o previas afirmaciones como la posibilidad de tener lenguas con un patrón shíbrido<. Para llevar a cabo esta investigación optamos por seguir la metodología original en estos estudios y obtener datos a través de las Historias de la rana. Datos que necesitarán ser ampliados en futuras investigaciones a través de otras herramientas de elicitación (p. ej., narraciones libres, traducciones, experimentos psicolingüísticos, etc.) y otros análisis complementarios (p. ej., gestualidad), pero que constituyen una base sólida para justificar los resultados que pasamos a discutir.

El resultado más importante es que existe variación intratipológica en las lenguas romances pero sólo con respecto al componente de Camino, y no en lo que se refiere al componente de Manera. Los hablantes de estas tres lenguas románicas se comportan de forma similar, y tal y como se les adjudica a las lenguas de marco verbal, a la hora de caracterizar la Manera; es decir, la descripción de este elemento es escasa, especialmente si se compara con la lengua de marco de satélite que hemos utilizado como referencia en este trabajo: el alemán.

La variación intratipológica se encuentra en el componente de Camino. A pesar de que no se espera que las lenguas de marco verbal describan este componente más allá del verbo principal o, si es caso, con algún elemento complementario, los datos demuestran que el italiano no sigue esta tendencia; al contrario, los hablantes de esta lengua ofrecen descripciones detalladas, ya que no solo prefieren utilizar construcciones de verbos-más-base, sino también mencionar más de un único elemento por verbo. Este comportamiento hace que existan diferencias significativas del italiano con respecto al español y al francés, pero no con respecto al alemán.

Estos resultados son muy importantes para la tipología de Talmy en general, puesto que demuestran que la variación intratipológica no solamente se da entre lenguas que pertenecen a una misma familia genética como se había demostrado en estudios 
anteriores (cf. Filipović 2007, Ibarretxe-Antuñano 2004a, b), sino también entre lenguas de un mismo grupo genético. Además, estos resultados también son interesantes para las propuestas sobre la existencia de escalas de saliencia que complementan la tipología bipartita talmiana. Ibarretxe-Antuñano (2009) muestra en un estudio con 24 lenguas que, independientemente del patrón de lexicalización principal que tengas las lenguas, éstas también se pueden clasificar con respecto a la cantidad de información que ofrecen sobre el componente semántico de Camino, y así ocupar diferentes posiciones a lo largo de un continuo o escala de saliencia. Los datos analizados situarían al italiano más cerca del alemán que de sus dos lenguas hermanas, y si tuviéramos que ordenar las tres lenguas románicas en esta escala del Camino, tendríamos primero el italiano, seguido del español y finalmente el francés.

Hemos también argüido que, posiblemente, esta clasificación del italiano como una lengua de saliencia alta de Camino, pueda explicarse, al menos en parte, por la predisposición que existe en esta lengua a utilizar estructuras verbales compuestas de un verbo más un adverbio direccional (cadere giú >caer abajo<), los denominados verbos sintagmáticos. Ahora bien, una cuestión que queda aún por responder es si estos adverbios direccionales pueden clasificarse como satélites (Iacobini/Masini 2007) y, por ende, clasificar al italiano como una lengua de marco de satélite (Simone 2008).

Con respecto a la primera cuestión, si bien es cierto que el italiano tiene una gran variedad de estos elementos y los hablantes los usan en sus descripciones como hemos visto, hay aún algunos factores que se tienen que tener en cuenta. Primero, estos adverbios no son exclusivos del italiano, sino que existen en otras lenguas románicas (español abajo, francés après). Otras lenguas de marco verbal también presentan estructuras similares como en el turco (disariya >a afuera<) o el euskera (behe-ra parte.baja-adl `a abajo<) entre otros. Segundo, el uso, la versatilidad y la productividad de estos elementos en italiano dista mucho de parecerse al de los satélites en una lengua como el alemán. Frente a los cuatro tipos de adverbios direccionales (via >de aquí<, fuori >fueraく, giù >abajo $<$ y dietro >detrás $<$ ) y las doce combinaciones con verbo que encontrábamos en italiano, los datos de alemán de nuestro estudio revelan trece satélites diferentes y más de treinta combinaciones, a lo que hay que añadir otras combinaciones con elementos deícticos (hin- >allík, her- >aquí<), además de su uso habitual en todas las narraciones. Por ello, pensamos que el llamar a estos elementos satélites e incluirlos en la misma categoría que los del alemán no es del todo acertado; por un lado, porque si no habría que argüir que los satélites existen en todas las lenguas ya que tienen elementos 
similares a los del italiano, y por otro lado, porque sus características morfosintácticas y discursivas difieren de los tradicionales satélites de una lengua como el alemán. Por tanto, creemos que es más objetivo denominarlos, por el momento, "pseudosatélites", al menos hasta que el propio concepto de satélite de Talmy, hoy en día problemático y criticado (véase Beavers 2008, Beavers e. a. 2010, entre otros) se modifique.

Así mismo, en relación a la pertenencia del italiano al grupo de lenguas de marco de satélite, también pensamos que no hay suficientes argumentos como para establecer un cambio de grupo tipológico. Es cierto que el italiano describe el Camino más que otras lenguas romances como el español y el francés, pero lo que demuestra este comportamiento es que ésta es una lengua con saliencia alta de Camino, característica que se aplica a otras lenguas de este patrón de lexicalización. Además, otro aspecto que hay que tener en cuenta es que en la tipología de Talmy los patrones se establecen de acuerdo con aquellas construcciones que son más características a la hora de describir el evento de movimiento; en ningún momento, se dice que las lenguas no tengan otros recursos lingüísticos para tal fin. La estructura característica del italiano se corresponde a las lenguas de marco verbal, máxime si se tiene en cuenta que con respecto al componente de Manera, el italiano no presenta ningún problema.

Estas mismas cuestiones se han planteado con respecto al francés, ya que algunos autores han clasificado al francés como una lengua híbrida (Pourcel/Kopecka 2005, Porquier 2001, 2003), y a sus prefijos verbales como satélites (Kopecka 2004, 2006). Sin embargo, no hemos encontrado en nuestros datos ningún atisbo de que el francés no se comporte como una lengua de marco verbal, aún más prototípica si cabe que el español. Los prefijos franceses no solo existen en las demás lenguas romances, sino que también son poco productivos. En los datos del francés hemos encontrado solamente dos pares que puedan ilustrar este posible carácter satelital. Amener >llevar/traer` en oposición a emmener >llevar`, y décrocher >descolgar en contraposición con accrocher >enganchar<. El prefijo que más tipos de verbos produce es el iterativo re- en repartir >volver a partirく (en oposición a partir >irse, partir $<$ ), retouner >volver y revenir >volver a venir . Hay, por supuesto, otros verbos con prefijo, como parcourir >recorrer` o descendre >descender`, pero éstos, como ocurre con los mismos casos en español y en italiano, están ya muy lexicalizados en la lengua como para identificarlos como prefijos actualmente. La frecuencia de estos verbos en los datos es además mínima (una o dos ocurrencias por verbo), por lo que no se pueden considerar estructuras características de la descripción del movimiento como tal. 
La cuestión de que el francés pudiera ser una lengua híbrida tampoco se sustenta. El estilo retórico de los hablantes franceses sigue paso a paso, aún más estrictamente que el español, los rasgos típicos de una lengua de marco verbal: poca descripción del componente de Manera y poca caracterización del componente de Camino fuera del verbo principal. Estos resultados revelan la importancia de contar con datos empíricos suficientes para sustentar las afirmaciones que se arrojan sobre la clasificación de las lenguas en la tipología talmiana; clasificación que, volvemos a insistir, se sustenta en el uso característico no en el inventario de construcciones posibles de una lengua. Algunos autores como Kopecka, Porquier o Pourcel parecen no tener en cuenta esta premisa fundamental de la teoría de Talmy.

En resumen, el español, el italiano y el francés son lenguas que pertenecen al patrón de lexicalización verbal, pero que muestran variación intratipológica con respecto al componente de Camino. El italiano frente al español y, especialmente, al francés es una lengua de saliencia alta de Camino. Estos resultados son importantes, pero también constituyen el primer paso para un futuro trabajo más extenso sobre las lenguas románicas y su posición con respecto a los patrones de lexicalización. El análisis de estas tres lenguas debería extenderse a otras lenguas de esta familia tanto mayoritarias (p. ej., portugués, rumano), como minoritarias (p. ej., aragonés, occitano). La evolución de las lenguas románicas minoritarias, según se desprende de estudios sobre el retorrománico (Berthele 2006, Vicario 1997) y el aragonés (HijazoGascón/Ibarretxe-Antuñano 2010), parece que ha seguido otro camino diferente, más conservador con respecto a algunas de las construcciones satelitales del patrón de lexicalización latino. Futuras investigaciones deberán de aportar más datos empíricos para comprobar cómo los hablantes de estas lenguas describen el espacio y el movimiento. Otro aspecto que también habría que tener en cuenta a la hora de ampliar el repertorio de lenguas románicas es la influencia y el contacto que las lenguas románicas han tenido con lenguas de diferente filiación genética y tipológica, así como su devenir histórico y evolución diacrónica. Conocidos son los casos de la relación entre el alemán y el romanche suizo con respecto al movimiento (Berthele 2006), pero aún quedan por explorar muchos otros como, por ejemplo, la descripción del rumano y la posible influencia con lenguas eslavas. Este tipo de trabajos no solo señalarían posibles influencias entre estas lenguas, sino que podrían explicar las causas de la variación intratipológica que pudiera existir. También sería interesante la investigación sobre las diferencias diatópicas entre diferentes variedades de estas lenguas románicas. Algunos 
trabajos iniciales sobre el español apuntan a que se pueden observar diferencias (Ibarretxe-Antuñano/Hijazo-Gascón 2012), pero aún faltan análisis más detallados no solo sobre el español, sino sobre otras lenguas que dada su extensión geográfica y contacto con diversas lenguas podría revelar interesantes resultados (p. ej., portugués europeo-portugués brasileño-portugués africano). En definitiva, a la andadura que hemos iniciado en este trabajo con respecto a la tipología semántica del movimiento en las lenguas románicas le queda aún un largo y posiblemente fructuoso camino por recorrer.

Referencias

Alcina J./J. M. Blecua (1975): Gramática española. Barcelona: Ariel.

Amenta, L. (2008): »Esistono i verbi sintagmatici nel dialetto e nell'italiano regionale di Sicilia?«, en: M. Cini (Ed.): I verbi sintagmatici in italiano e nelle varietà dialettali. Stato dell'arte e prospettive di ricerca. Fráncfort: Peter Lang, 159174.

Aske, J. (1989): »Path predicates in English and Spanish: A closer look«, en: Proceedings of the 15th Annual Meeting of the Berkeley Linguistics Society. Berkeley, CA: Berkeley Linguistics Society, 1-14.

Baicchi, A. (2005): »Translating phrasal combinations across the typological divide «, en: M. Bertucelli Papi (Ed.): Studies in the Semantics of Lexical Combinatory Patterns. Pisa: Pisa University Press, 487-519.

Bally, C. (1965): Linguistique générale et linguistique française. Berna: Francke.

Bamberg, M. (1994): »Development of linguistic forms: German«, en R. Berman/D. Slobin (Eds.): Relating events in Narrative. A Cross linguistic Development Study. Mahwah, NJ: Lawrence Erlbaum, 189-238.

Beavers, J. (2008): »On the nature of goal marking and delimitation: evidence from Japanese«, Journal of Linguistics 44: 183-316.

Beavers, J. e. a. (2010): »The typology of Motion Expressions Revisited«, Journal of Linguistics 44, 183-316.

Berman, R./D. Slobin (Eds.) (1994): Relating events in narrative. A Cross Linguistic Developmental study. Hillsdale, NJ: Lawrence Erlbaum.

Bernini, G. (2008): »Per una definizione di verbi sintagmatici. La prospettiva dialettale «, en: M. Cini (Ed.): I verbi sintagmatici in italiano e nelle varietà 
dialettali. Stato dell'arte e prospettive di ricerca. Fráncfort: Peter Lang, 141158.

Berthele, R. (2004): »The typology of motion and posture verbs: a variationist account «, en: B. Kortmann (Ed.): Dialectology meets typology. Berlin/New York: Mouton de Gruyter, 93-126.

Berthele, R. (2006): Ort und Weg. Eine vergleichende Untersuchung der sprachlichen Raumreferenz in Varietäten des Deutschen, Rätorromanischen und Französichen. Berlín: Mouton de Gruyter.

Cadierno, T./P. Robinson (2009): »Language typology, task complexity and the develompent of L2 lexicalization patterns for describing motion events«, Annual Review of Cognitive Linguistics 7, 245-276.

Cardini, F. E. (2008): »Manner of motion saliency: An inquiry into Italian«, Cognitive Linguistics 19 (4), 533-569.

Cifuentes Honrubia, J. L. (1999): Sintaxis y semántica del movimiento: Aspectos de Gramática Cognitiva. Valencia: Instituto de Cultura Juan Gil-Albert.

Cifuentes-Férez, P. (2010): »The semantics of the English and the Spanish motion verb lexicons«, Review of Cognitive Linguistics, 8(2), 233-271.

Cini, M. (Ed.) (2008): I verbi sintagmatici in italiano e nelle varietà dialettali. Stato dell'arte e prospettive di ricerca. Fráncfort: Peter Lang.

Cordin, P. (2008). „L'espressione di tratti aspettuali nei verbi analitici dei dialetti trentini«, en: M. Cini (Ed.): I verbi sintagmatici in italiano e nelle varietà dialettali. Stato dell'arte e prospettive di ricerca. Fráncfort: Peter Lang, 175192.

Croft, W. e. a. (2010): »Revising Talmy's typological classification of complex constructions«, en: H. C. Boas (Ed.): Contrastive studies in construction grammar. Amsterdam: John Benjamins, 201-236.

Ferrari, G./M. Mosca (2010): »Some constructions of Path: From Italian to some Classical languages«, en: G. Marotta e. a. (Eds.) Space in language. Proceedings of the Pisa International Conference. Florencia: Edizioni ETS, 317-338.

Filipović, L. (2007): Talking about motion. A crosslinguistic investigation of lexicalisation patterns. Amsterdam/Filadelfia: John Benjamins.

Gennari, S. P. e. a. (2002): »Motion events in language and cognition«, Cognition 83, 49-79. 
Guo, J. e. a. (Eds.) (2010): Crosslinguistic Approaches to the Psychology of Language: Research in the Tradition of Dan Isaac Slobin. Nueva York: Psychology Press.

Gullberg, M. e. a. (2008): »Learning to talk and gestures about motion in French«, First Language 28(2), 200-236.

Han, Z./T. Cadierno (Eds.) (2010): Linguistic Relativity in Second Language Acquisition. Thinking for Speaking. Bristol: Multilingual Matters.

Hendriks, H. e. a. (2008): »How adult English learners of French express caused motion: A comparison with English and French natives«, Acquisition et Interaction en Langue Étrangère (AILE) 27, 15-41.

Hickmann, M. (2006): »The relativity of motion in first language acquisition«, en: M. Hickmann/S. Robert (Eds.): Space across languages: linguistic systems and cognitive categories. Amsterdam: John Benjamins, 281-308.

Hickmann, M. (2007): »Static and dynamic location in French: Developmental and cross-linguistic perspectives«, en: M. Aurnage e. a. (Eds.) The categorization of spatial entities in language and cognition. Amsterdam: John Benjamins, 205231.

Hickmann, M./H. Hendriks (2006): »Static and dynamic location in French and English«, First Language 26(1), 103-135.

Hickmann, M./H. Hendriks (2010): »Typological constraints on the acquisition of spatial language in French and English«, Cognitive Linguistics 21(2), 189-215.

Hickmann, M. e. a. (2009). »Typological constraints on motion in French and English child language«, en: J. Guo e. a. (Eds.) Crosslinguistic approaches to the psychology of language. Research in the tradition of Dan Isaac Slobin. Nueva York: Psychology Press, 209-224.

Hijazo-Gascón, A. (2011): La expresión de eventos de movimiento y su adquisición en segundas lenguas. Tesis Doctoral inédita, Zaragoza: Universidad de Zaragoza.

Hijazo-Gascón, A./I. Ibarretxe-Antuñano (2010): „Tipología, lexicalización y dialectología aragonesa«, Archivo de Filología Aragonesa 66, 245-280.

Iacobini, C. (2009): »The role of dialects in the emergence of Italian phrasal verbs«, Morphology 19(1), 15-44.

Iacobini, C./F. Masini (2007a): »The emergence of verb-particle constructions in Italian: locative and actional meanings«, Morphology 16(2), 155-188.

Iacobini, C./F. Masini (2007b): »Verb-particle constructions and prefixed verbs in Italian: typology, diachrony and semantics«, en: G. Booij e. a. (Eds.): On-line 
Proceedings of the Fifth Mediterranean Morphology Meeting (MMM5) (Fréjus, 15-18 september 2005). Bolonia: Università degli Studi di Bologna, 157-184.

Ibarretxe-Antuñano, I. (2004a): »Language typologies in our language use: the case of Basque motion events in adult oral narratives«, Cognitive Linguistics 15(3), 317349.

Ibarretxe-Antuñano, I. (2004b): »Dicotomías frente a continuos en la lexicalización de eventos de movimiento«, Revista española de lingüistica 34(2), 481-510.

Ibarretxe-Antuñano, I. (2006): Sound symbolism and motion in Basque. Munich: Lincom Europa.

Ibarretxe-Antuñano, I. (2009): »Path salience in motion events«, en: J. Guo e. a. (Eds.): Crosslinguistic Approaches to the Psychology of Language: Research in the Tradition of Dan Isaac Slobin. Nueva York: Psychology Press, 403-414.

Ibarretxe-Antuñano, I. (2010): »Cuestiones pendientes de la tipología semántica para el análisis de los eventos de movimiento«, en: J. F. Val Álvaro/M. C. Horno Chéliz (Eds.) La gramática del sentido: léxico y sintaxis en la encrucijada. Zaragoza: PUZ, 102-122.

Ibarretxe-Antuñano, I./A. Hijazo-Gascón (2012): »Variation in motion events: Theory and applications«, en: L. Filipović y K. M. Jaszcolt (Eds.): Space and Time across Languages and Cultures, Volume I: Linguistic Diversity. Amsterdam/Filadelfia: John Benjamins, 349-371.

Khalifa, J.-C. (2001): »Linguistique et traduction: le cas des verbes de déplacement«, Anglophonia 10, 199-213.

Kopecka, A. (2004): Étude typologique de l'expression de l'espace: localisation et déplacement en français et en polonais. Lyon: Université Lumière Lyon 2.

Kopecka, A. (2006): »The semantic structure of motion verbs in French: Typological perspectives«, en: M. Hickmann/S. Robert (Eds.): Space in languages: Linguistic systems and cognitive categories. Amsterdam/Filadelfia: John Benjamins, 83-101.

Kopecka, A. (2009): „L'expression du déplacement en français: l'interaction des facteurs sémantiques, aspectuels et pragmatiques dans la construction du sens spatial«, Langages 173, 54-75.

Kopecka, A. (en prensa): »From a satellite- to a verb-framed pattern: A typological shift in French«, en: H. W. De Mulder y T. Mortelmans (Eds.): Variation and change in adpositions of movement. Amsterdam/Filadelfia, John Benjamins. 
McNeill, D. (2000): »Analogic/Analytic representations and cross-linguistic differences in thinking for speaking «, Cognitive Linguistics 11, 43-60

Masini, F. (2005): »Multi-word Expressions between Syntax and the Lexicon: the case of Italian Verb-particle Constructions«, SKY Journal of Linguistics 18, 145-173.

Masini, F. (2008): »Verbi sintagmatici e ordine delle parole«, en: M. Cini (Ed.): I verbi sintagmatici in italiano e nelle varietà dialettali. Stato dell'arte e prospettive di ricerca. Fráncfort: Peter Lang, 83-102.

Mendikoetxea, A. (1999): »Construcciones inacusativas y pasivas«, en: I. Bosque/V. Demonte (Eds.): Gramática descriptiva de la lengua española. Madrid: Espasa, 1575-1629.

Morimoto, Y. (2001): Los verbos de movimiento. Madrid: Visor Libros.

Naigles, L. e. a. (1998): »Speaking of motion: Verb use by English and Spanish speakers«, Language and Cognitive Processes 13(5), 521-549.

Ochsenbauer, A.-K. (2010): The impact of language-specific factors in first language acquisition: The expression of motion in French and German. Tesis doctoral inédita: París/Munich, Université Paris 8 Vincennes/Ludwig-MaximiliansUniversität München.

Özçalıskan, S. (2004): »Encoding the manner, path and ground components of a metaphorical motion event«, Annual Review of Cognitive Linguistics 2, 73-102.

Özçalışkan, Ş./D. Slobin (2003): »Codability effects on the expression of Manner of motion in Turkish and English«, en: A. S. Özsoy e. a. (Eds.): Studies in Turkish linguistics. Estambul: Boğaziçi University Press, 259-270.

Papafragou, A. e. a. (2002): »Shake, rattle, 'n' roll: the representation of motion in language and cognition«, Cognition 84, 189-219.

Porquier, R. (2001): »Il m'a sauté dessus', ‘je lui ai couru après': un cas de postposition en français«, Journal of French Language Studies 11, 123-134.

Porquier, R. (2003): »'Gli corro dietro/Je lui cours après'. A propos d'une construction verbale spécifique en italien et en français«, en: M. Giacomo-Marcellesi y A. Rocchetti (Eds.): Il verbo italiano. Studi diacronici, sincronici, contrastivi, didattici. Roma: Bulzoni, 491-500.

Pourcel, S./A. Kopecka (2005): »Motion expression in French: Typological diversity«, Durham and Newcastle Working Papers in Linguistics 11, 139-153.

Real Academia Española de la Lengua (RAE) (2009): Nueva gramática de la lengua española. Madrid: Espasa Calpe. 
Schwarze, C. (1985): »Uscire e andare fuori: struttura sintattica e semantica lessicale«, en: A. Franchi De Bellis/L. M. Savoia (Eds.): Sintassi e morfologia della lingua italiana d'uso. Teoria ed applicazioni descrittive. SLI XXIV. Roma, Bulzoni, 355-371.

Schwarze, C. (2008): »I verbi sintagmatici: prospettive di ricerca«, en: M. Cini (Ed.): I verbi sintagmatici in italiano e nelle varietà dialettali. Stato dell'arte e prospettive di ricerca. Fráncfort: Peter Lang, 209-223.

Sebastián, E./D. Slobin (1994): »Development of Spanish forms: Spanish«, en: R. Berman/D.Slobin (Eds.): Relating events in narrative: A crosslinguistic developmental study. Hillsdale, NJ: Lawrence Erlbaum, 239-284.

Simone, R. (1996): »Esistono verbi sintagmatici in italiano?«, Cuadernos de Filología Italiana 3, 47-61.

Simone, R. (2008): »Verbi sintagmatici come costruzione e come categoría«, en: M. Cini (Ed.): I verbi sintagmatici in italiano e nelle varietà dialettali. Stato dell'arte e prospettive di ricerca. Fráncfort: Peter Lang, 13-30.

Slobin, D. (1991): »Learning to think for speaking. Native language, cognition and rhetorical style«. Pragmatics 1, 7-29.

Slobin, D. (1996): »Two ways to travel: Verbs of motion in English and Spanish«, en: M. Shibatani/S. A. Thompson (Eds.): Grammatical constructions. Their Form and Meaning. Oxford: Clarendon Press, 195-317.

Slobin, D. (1997): »Mind, Code and Text«, en: J. Bybee e. a. (Eds.): Essays on language function and language type: Dedicated to T. Givón. Amsterdam: John Benjamins, 437-467.

Slobin, D. (2000): »Verbalized events. A dynamic approach to linguistic relativity and determinism«, en: S. Niemeier/R. Dirven (Eds.) Evidence for linguistic relativity. Amsterdam: John Benjamins, 107-138.

Slobin, D. (2003): »Language and thought online: Some consequences of linguistic relativity«, en: D. Gentner/S. Goldin-Meadow (Eds.): Language in Mind: Advances in the Investigation of Language and Thought. Cambridge, MA: MIT Press, 157-191.

Slobin, D. (2004): »The many ways to search for a frog: Linguistic typology and the expression of motion events«, en: S. Strömqvist y L. Verhoeven (Eds.): Relating events in narrative: Typological and contextual perspectives. Hillsdale, NJ: Lawrence Erlbaum Associates, 219-257. 
Slobin, D. (2006): „What makes Manner of motion salient? Explorations in linguistic typology, discourse and cognition«, en: M. Hickmann/S. Robert (Eds.) Space in Languages: Linguistic Systems and Cognitive Categories. Amsterdam: John Benjamins, 59-82.

Slobin, D./N. Hoiting (1994): »Reference to movement in spoken and signed languages: Typological considerations«, en: S. Gahl e. a. (Eds.): Proceedings of the 20th Annual Meeting of the Berkeley Linguistics Society. Berkeley, CA: Berkeley Linguistics Society, 487-503.

Slotova, N. (2008): »From Satellite-framed Latin to Verb-Framed Romance. Late Latin as an intermediary stage«, en: R. Wright (Ed.): Latin vulgaire - latin tardif VIII. Actes du VIIIe colloque international sur le latin vulgaire et tardif. Oxford, 6-9 settembre 2006. Zürich/Nueva York, Olms-Weidmann, 253-262.

Spreafico, L. (2008a): »Tipologie di lessicalizzazione degli eventi di moto nelle lingue dell'Area linguistica Carlomagno«, en: E. Cresti (Ed.): Prospettive nello studio del lessico italiano: atti del IX Congresso SILFI, Firenze, 14-17 giugno 2006. Florencia, Firenze University Press.

Spreafico, L. (2008b): »Tipologie di lessicalizzazioni adverviali in alcune lingue d'Europa«, en: M. Cini (Ed.): I verbi sintagmatici in italiano e nelle varietà dialettali. Stato dell'arte e prospettive di ricerca. Fráncfort, Peter Lang, 61-81.

Strömqvist, S./L. Verhoeven (Eds.) (2004): Relating Events in Narrative.Typological and Contextual Perspectives. Hillsdale, NJ: Lawrence Erlbaum Associates.

Sujiyama, Y. (2005): „Not all verb-framed languages are created equal: The case of Japanese«, Proceedings of the thirty-first annual meeting of the Berkeley Linguistics Society, 299-310.

Talmy, L. (1985): »Lexicalization patterns: Semantic struture in lexical forms«, en T. Shopen (Ed.): Language Typology and Syntactic Description, Vol. 3: Grammatical categories and the lexicon. Cambridge: Cambridge University Press, 36-149.

Talmy, L. (1991): »Path to realization: A typology of event conflation«, Proceedings of the Seventeenth Annual Meeting of the Berkeley Linguistic Society, 480-519.

Talmy, L. (2000): Toward a cognitive semantics. Cambridge, MA: The MIT Press.

Tesnière, L. (1959): Élements de syntaxe structurale. París: Klincksieck.

Vicario, F. (1997): I verbi analitici in friulano. Milán: Franco Angeli. 
